\title{
SOBRE PENTEADOS E CABELOS AFRICANOS: VISÕES \\ EUROCÊNTRICAS NAS PÁGINAS DA EU SEI TUDO (1917-1929)
}

\section{ON HAIRSTYLES AND AFRICAN'S HAIR: VISIONS EUROCENTRIC ON THE PAGES OF EU SEI TUDO (1917-1929)}

DOI: http//dx.doi.org/10.15448/2178-3748.2017.1.22463

\author{
Ana Carolina Carvalho Guimarães \\ Mestranda em Educação - Universidade de São Paulo \\ ana.carolina.guimaraes@usp.br
}

\begin{abstract}
RESUMO: Este artigo analisa imagens e textos relativos às mulheres africanas, publicados na revista ilustrada Eu Sei Tudo entre os anos de 1917 e 1929. A hipótese desenvolvida é a de que este periódico contribuiu para a difusão de representações e estereótipos da cultura e das mulheres africanas, especialmente quando se considera que esta revista, originalmente francesa, era produzida no Brasil a partir dos exemplares que circulavam naquele país. Buscou-se, então, dar enfoque à maneira como a revista e o almanaque Eu Sei Tudo, publicado anualmente entre 1921 e 1958, veiculavam ilustrações e informações sobre os cabelos das mulheres africanas. Neste sentido, conclui-se que preponderou nesse periódico uma visão eurocêntrica de mundo, a partir da qual eram apresentadas ideias de modernidade e civilização que, frequentemente, tinham nos modos de tratamento da África e dos africanos o seu oposto.
\end{abstract}

PALAVRAS-CHAVE: Representação. Estereótipo. Mulheres africanas.

ABSTRACT: This article analyzes images and texts related to African women, published in the illustrated magazine EuSeiTudo between the years 1917 and 1929. The hypothesis developed is that the journal contributed to the diffusion of representations and stereotypes of African women and its culture, especially when you consider that this magazine, originally French, wasalso produced in Brazil through copies that circulated in that country. Thereon, we sought to focus on the manner the magazine and the Almanac EuSeiTudo, published annually between 1921 and 1958, displayed illustrations and information on the hair of African women. In this sense, prevailed in this period a Eurocentric worldview, from which, it is concluded, were presented ideas of modernity and civilization, that often had the modes of treatment of Africa and Africans its opposite.

KEYWORDS:Representation. Stereotype.African women. 


\section{As influências europeias nas representações da beleza feminina africana}

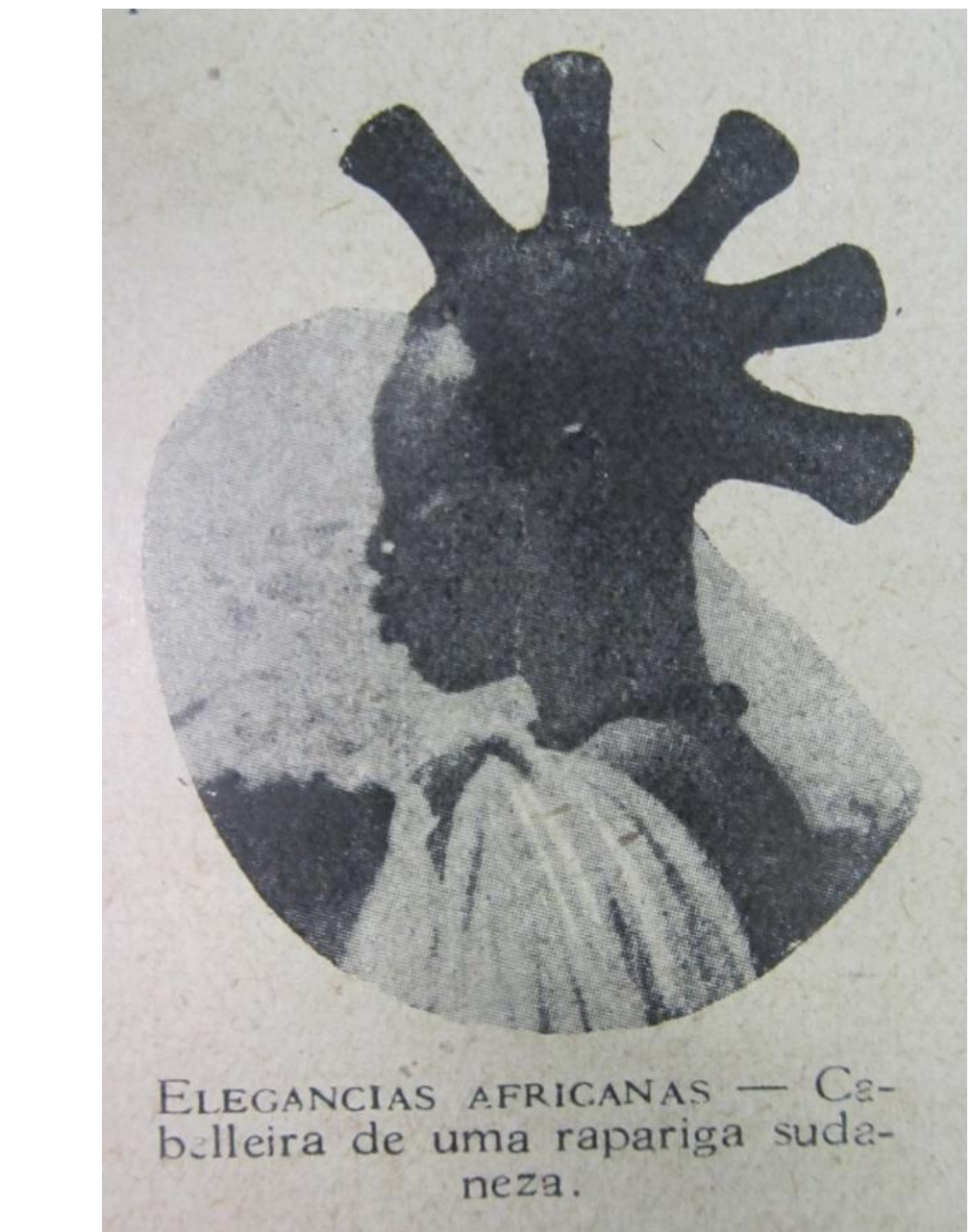

Figura 1 - "Elegancias Africanas - Cabelleira de uma rapariga sudanesa.". Fonte: AlmanachEu Sei Tudo, 1928, p. 221.

Este artigo tem como objetivo tratar da construção de representações acerca das mulheres africanas através dos cabelos femininos africanos contrapostos, em imagens e textos da revista Eu Sei Tudo, aos padrões de beleza europeus e discute, ainda, o imaginário social que tais representações alimentavam. Esse magazine foi uma versão nacional de uma publicação homônima, a Je Sais Tout, que circulou na França entre 1905 e 1939; no Brasil, foi editada entre junho de 1917 e dezembro de 1958. No período aqui recortado para análise, entre 1917 e 1929, ainda era forte a presença de um ideário francófono de civilização, modernidade $^{1}$ e cultura entre nós. Além disso, em sua versão brasileira, de forma integral ou

\footnotetext{
${ }^{1}$ A noção de modernidade é pensada neste artigo a partir de Bermann (1987, p. 16): "grandes descobertas nas ciências físicas, com a mudança da nossa imagem do universo e do lugar que ocupamos nele; a industrialização da produção, que transforma conhecimento científico em tecnologia, cria novos ambientes humanos e destrói os antigos, acelera o próprio ritmo da vida, gera novas formas de poder corporativo e de luta de classes; descomunal explosão demográfica, que penaliza milhões de pessoas arrancadas de seu habitat ancestral, empurrando - as pelos caminhos do mundo em direção a novas vidas; rápido e muitas vezes catastrófico crescimento urbano; sistema de comunicação de massa, dinâmicos em seu desenvolvimento, que embrulham e amarram no mesmo
}

Oficina do Historiador, Porto Alegre, EDIPUCRS, v. 10, n. 1, jan./jun. 2017, 
resumida, trechos, seções, imagens e matérias que eram veiculados na ediçãofrancesa permitem reconhecer a circulação de ilustrações entre dois mundos bem como investigar a difusão do imaginário francês de civilização no Brasil.

A revista Eu Sei Tudopropunha-se a retratar o cotidiano, apresentava gestos, costumes, gostos e condutas, difundindo - de acordo com a ideia que defendiam sobre o que consideravam "civilizado" - modelos de homem e mulher civilizados e por meio da grande quantidade de imagens e dos diversos assuntos tratados, buscava representar uma concepção de modernidade e criar em seus leitores sensibilidades que caminhassem ao encontro de costumes modernos e urbanos.

Compreender os conteúdos da Je Sais Tout e da Eu Sei Tudo implica compreender também os contextos do domínio imperialista sobre vastas áreas do território africano e uma certa noção de cultura produzida naquele momento. O lançamento da revista francesa se deu em 1905, quando a França dominava o Marrocos, a Argélia, Camarões, Congo, Senegal, Tunísia, Guiné, Costa do Marfim, entre outros países. No Brasil, a Eu Sei Tudo começou a ser publicada em 1917, durante a Primeira Guerra Mundial (1914-1918), conflito diretamente ligado à corrida imperialista dos países europeus.

O imperialismo pode ser definido como a busca, por parte de países europeus, pela ampliação de seu controle, domínio e influência sobre áreas férteis em matéria-prima e mão de obra barata, cuja exploração alimentava a pujança das novas metrópoles. Com isso, expandiam sua economia e difundiam também seus hábitos, costumes e cultura. Foi nesse contexto que padrões europeus de comportamento, visões europeias de mundo e uma noção eurocêntrica de "civilização" foram se instaurando em parte significativa do mundo. ${ }^{2}$

pacote, os mais variados indivíduos e sociedades; Estados nacionais cada vez mais poderosos, burocraticamente estruturados e geridos, que lutam com obstinação para expandir seu poder; movimentos sociais de massas e de nações, desafiando seus governantes políticos ou econômicos, lutando por obter algum controle sobre suas vidas; enfim, dirigindo e manipulando todas as pessoas e instituições, um mercado capitalista mundial, drasticamente flutuante, em permanente expansão".

2 No livro "A Invenção da África" (2013) Mudimbe problematiza uma questão anterior ao imperialismo: a colonização dos países africanos. Para o autor a análise da experiência colonial - "período ainda contestado e controverso" (20031, p. 15) - é de suma importância, visto que explica as configurações históricas e os discursos sobre a cultura africana conferindo uma representação e significado à África diferentes dos atribuídos por estudiosos que buscam legitimar uma filosofia africana enquanto um sistema de conhecimentos construídos pelos próprios africanos.Com o colonialismo os hábitos, costumes e cultura dos países colonizadores tornaram-se modelos e definiram discursos (aos quais Mudimbe se refere como "discursos ocidentais") considerados verdades absolutas e que criaram, de acordo com o autor, as dicotomias "tradicionais versus moderno; oral versus escrito e impresso; comunidades agrárias e consuetudinárias versus civilização urbana e industrializada; economias de subsistência versus economias altamente produtivas”. (MUDIMBE, 2003, 18). Sendo assim, Mudimbe questiona quais vozes e fatores dominantes implicaram na "invenção" da África procurando construir um novo sentido sobre o conhecimento em África buscando romper com um sistema de pensamentos forjados sobre os países africanos que, segundo o autor, "pressupõem uma legitimidade epistemológica não - africana". (MUDIMBE, 2013, p. 10). 
Os padrões de cultura que se introduziam no Brasil, tendo em vista as mudanças no comportamento, nos gostos e nos gestos dos indivíduos, tinham uma intencionalidade, ainda que implícita, de "aprimorar" a cultura brasileira. Segundo Said, naquele momento, o conceito de cultura incluía

um elemento de elevação e refinamento, o reservatório de cada sociedade, no saber e no pensamento como disse Mathew Arnold na década de 1860. [...] A pessoa lê Dante ou Shakespeare para acompanhar o melhor do pensamento e do saber, e também, para ver a si mesma, a seu povo, sua sociedade, suas tradições sob as melhores luzes. Com o tempo, a cultura vem a ser associada, muitas vezes de forma agressiva, à nação ou ao Estado; isso "nos" diferencia "deles", quase sempre com algum grau de xenofobia. A cultura, neste sentido, é uma fonte de identidade, e aliás bastante combativa, como vemos em recentes "retornos" à cultura e à tradição. Esses "retornos" acompanham códigos rigorosos de conduta intelectual e moral, que se opõem à permissividade associada a filosofias relativamente liberais com o multiculturalismo e o hibridismo. (SAID, 2011, p. 11).

Assim, a cultura estava ligada a um rebuscamento do comportamento e dos gostos; associada, por exemplo, às artes, à música, à literatura, aos saberes científicos, às filosofias e algumas práticas urbanas cotidianas adotadas pela sociedade. A partir dessa percepção, a revista Eu Sei Tudo produzia uma referência sobrecultura que era tratada como superior. Por essa razão, operiódico veiculava tantas imagens e informações sobre os modos de vida europeus, essencialmente os franceses.

Said, ao fazer uma análise da construção narrativa de alguns romances escritos no século XIX, afirma que "o poder de narrar, ou de impedir que se formem e surjam outras narrativas, é importante para a cultura e o imperialismo, e constitui umas das principais conexões entre ambos" (SAID, 2011, p. 11); isso porque as narrativas evidenciam aquilo que é dominante, na relação que faz entre este e o que se considerava "inferior".

Neste trabalho, embora a análise feita seja a partir das ilustrações e suas legendas, é possível afirmar que estas compõem também uma narrativa, na qual as concepções de "civilização", de cultura e de modernidade são produzidas; neste processo, esta visão do progresso é construída na relação com o outro, o "bárbaro", o "primitivo", o "atrasado".

Foi também no contexto do imperialismo que teorias raciais se fortaleceram pois, na medida em que se tentava evidenciar os países europeus e sua população como avançados, buscava-se comprovar o atraso de outros países e povos, deste modo justificando, por critérios considerados científicos, o domínio e a exploração. O período que vai de meados do século XIX às décadas iniciais do XX assistiu à emergência de diversas teorias raciais que, fundamentadas no evolucionismo e no cientificismo, alicerçaram ideologicamente relações de 
domínio, exploração e discriminação entre grupos sociais, étnicos e países. Estudos sobre diferentes culturas e grupos étnicos propunham classificar, qualificar e distinguir as experiências humanas em diferentes tempos e lugares. Tais teorias buscavam sua legitimidade tanto pela categorização de diferenças físicas quanto de aspectos ligados à sociedade e à cultura.

Os meios de comunicação foram um dos lugares nos quais pode se dar o "aprendizado" e interiorização do racismo e é nesse sentido que o Magazine Mensal Ilustrado Eu Sei tudo se constituiu em fonte e objeto deste trabalho. As revistas ilustradas (ou de variedades) publicadas no Brasil no início do século XX também contribuíram para a veiculação de textos e imagens que produziam os pares culto/inculto, moderno/antigo, oferecendo aos leitores padrões de comportamento e visões de mundo alicerçadas nessas oposições.

Foram analisadas as edições mensais da Eu Sei Tudo publicadas de 1917, ano do lançamento da versão brasileira, até 1929. Isso porque, segundo Mauad (1990), a história das revistas ilustradas encontra um marco em 1928, quando a revista $O$ Cruzeiro é lançada. A adoção de uma linha editorial com fortes influências norte-americana, a "introdução de novas técnicas de impressão" (MAUAD, 1990, p. 212) e o aumento exorbitante no uso das fotos, numa dimensão antes desconhecida, alteram os padrões até então vigentes neste tipo de impresso.

Ao apresentar temas variados, com ênfase nas diversas formas de arte e na ciência, junto com reportagens ligadas a acontecimentos contemporâneos e assuntos como moda e beleza, esse tipo de periódico promoveu certos comportamentos em detrimento de outros; sua função educativa vinha assinalada já no próprio nome - Eu Sei Tudo - que, simultaneamente, pode significar tanto a possibilidade de aquisição de um conhecimento mais universal quanto a formação de si. Deste modo, mesmo que não fossem educativos em stricto sensu, esses periódicos contribuíram para a difusão de um modo de pensar noções de civilidade e de conceber padrões de modernização. E, ainda, serviram à divulgação científica, facilitando o acesso a conhecimentos antes mais restritos aos espaços acadêmicos. Sua periodicidade mensal, aliada a um requinte gráfico, os colocava entre o jornal e o livro, menos efêmeros que o primeiro e mais condensados que o segundo; a profusão de ilustrações os tornava atraentes inclusive para leitores mais rudimentares e, eventualmente, para iletrados.

A periodização considerou, ainda, o processo de fortalecimento e difusão do pensamento eugenista no Brasil, desde a fundação da Sociedade Paulista de Eugenia, em 1917, até a realização do Primeiro Congresso Brasileiro de Eugenia, em 1929. Assim, o 
recorte temporal escolhido procurou contemplar tanto a história das revistas ilustradas quanto a propagação dos discursos acerca da "pureza da raça" e seu uso na interpretação do Brasil (D’AVILA, 2006).

A tentativa de tratar das representações da África e dos africanos difundidas pela $E u$ Sei Tudo está ancorada em dois conceitos: o de representação e o de imaginário social. Segundo Chartier (1991) a noção de representação envolve tanto a imposição de caracterizações e classificações que um grupo "dominante" faz de outro grupo, contrapondose ao modo como este último define a si próprio, quanto a representação que cada grupo produz de si gerando entre os indivíduos uma identidade única e a ideia de unidade.

Ao trabalhar sobre as lutas de representação, cuja questão é o ordenamento, portanto a hierarquização da própria estrutura social, a história cultural separa-se sem dúvida de uma dependência demasiadamente estrita de uma história social dedicada exclusivamente ao estudo das lutas econômicas, porém opera um retorno hábil também sobre o social, pois centra a tenção sobre as estratégias simbólicas que determinam posições e relações e que constroem, para cada classe, grupo ou meio, um ser-percebido constitutivo de sua identidade. (CHARTIER, 1991, p. 182-184).

Assim, "as representações do mundo social seriam determinadas pelos interesses dos grupos que as forjam" (SANTOS, 2011, p. 34), ligadas as suas práticas sociais. Desta maneira, os sentidos produzidos pelas fotos e textos da Eu Sei Tudoprovocam um imaginário que é construído a partir das realidades firmadas pelas representações.Especificamente, operase neste artigo a noção de "imaginário social", tal como formulada por BronislawBaczko, entendida como um esquema de interpretação que

suscita a adesão a um sistema de valores e intervém eficazmente nos processos de sua interiorização pelos indivíduos, modelando os comportamentos, capturando as energias e, em caso de necessidade, arrastando os indivíduos à ação comum. (BACZKO, 1985, p. 311).

Segundo o autor,

É assim que, através dos seus imaginários sociais, uma colectividade designa a sua identidade; elabora uma certa representação de si; estabelece a distribuição dos papéis e das posições sociais; exprime e impõe crenças comuns; constrói uma espécie de código de 'bom comportamento', designadamente através da instalação de modelos formadores tais como o do "chefe", o "bom súbdito", o "guerreiro corajoso", etc. (BACZKO, 1985, p. 309). 
O imaginário social acerca do continente e das populações africanas foi moldado, entre outros elementos, por diferentes tipos de publicações, desde romances, passando por histórias em quadrinhos, até as revistas ilustradas como a Eu Sei Tudo ${ }^{3}$.

As representações que circularam na $E u$ Sei Tudo, especialmente sobre as mulheres africanas, influenciaram a construção de estereótipos que, embora tenham sido ressignificados ao longo do tempo, ainda persistem na atualidade. Nas páginas deste magazine ilustrado é possível verificar as diferenças estabelecidas entre as mulheres brancas e africanas, o enaltecimento da primeira e a folclorização da segunda. Tais contraposições reforçam a noção de que as revistas foram "espaços de divulgação e de construção de identidades e de memórias" (DOURADO, 2005, p. 78) que afirmavam a hierarquização entre os grupos étnicos. Quando se considera ainda que parte desses textos e imagens vinha do original francês, compreende-se que estavam carregados de um olhar eurocêntrico transposto sem grandes intervenções para o Brasil, contribuindo para a profusão de estereótipos culturais e raciais.

De acordo com Santos (2008), os estereótipos sociais se referem etimologicamente ao uso de "moldes fixos" para a classificação de pessoas, agrupadas em termos gerais segundo sua etnia, classe social, religião, biotipo, entre outros critérios. A construção dos estereótipos se dá por meio de diferenciações que geram protótipos, modelos, padrões que determinam uma (pseudo) concordância na maneira como são produzidas as representações; "dessa forma, a pessoa alvo do julgamento é como que revestida com os atributos que se supõe serem comuns aos membros de seus grupos, sendo, então, inferidas várias de suas características" (SANTOS, 2008, p. 7).

Investigando mecanismos usados nas páginas da Eu Sei Tudo, entre 1917 e 1929, observa-se que a veiculação de estereótipos oriundos do olhar sobre o outro, encontrou nos cabelos das mulheres africanas, fotografados e legendados, um de seus principais alvos. Embora importantes discussões já tenham sido realizadas e alguns avanços possam ser vistos, alguns daqueles estereótipos ainda hoje persistem.

O que apresentamos a seguir é um fragmento desse processo, estudado a partir de um pressuposto e de uma hipótese: o pressuposto é o de que a educação acontece na escola, mas também, de forma difusa e assistemática, por meio dos veículos de comunicação, entre outras

\footnotetext{
${ }^{3}$ Said trabalha em seu texto Cultura e Imperialismo com romances do século XIX para evidenciá-los "como parte da relação entre cultura e império" (SAID, 2011, p.24), como faz, por exemplo, na análise da obra de Joseph Conrad, Nostromo, na qual está enraizada uma visão ocidental de mundo que impede o autor de considerar "outras história, outras culturas e outras aspirações". (SAID, 2011, p. 18) O clássico As aventuras de Tintim, história em quadrinhos criada em 1929 pelo belga Hergé, as narrativas que retratam o personagem na África (Tintim na África) são da década de 1930 e demonstram um ideal "civilizador" atribuído ao branco europeu numa clara alusão à ideia do "fardo do homem branco".
} 
práticas; a hipótese é a de que um desses veículos, a revista $E u$ Sei Tudo, teve papel importante na difusão de uma perspectiva eurocêntrica de análise do mundo africano que, considerando a realidade brasileira e seu recente passado escravista, contribuía para que seus leitores olhassem o Brasil com olhos estrangeiros e reproduzissem, com esta lente, o preconceito lá existente.

\section{Sobre a revista e o almanaque $\mathrm{Eu}$ Sei Tudo}

A Eu Sei Tudo circulou no Brasil entre junho de 1917 e dezembro de 1958, editada no Rio de Janeiro pela Companhia Editora Americana e teve origem em um periódico homônimo francês, a revista Je Sais Tout, publicada entre 1905 e 1939. Era uma revista mensal, com algumas páginas de papel couchê, geralmente composta por cerca de 150 páginas. A partir de 1920, porém, passou a ter aproximadamente 125 páginas. No que se refere a sua estrutura interna, observa-se a inserção dos anúncios no início e ao final de cada edição. Com o decorrer dos anos, a revista ampliou os espaços para publicidade, o que pode ser percebido tanto como negócio quanto como indício da expansão do público leitor, que tornava o veículo mais atrativo aos olhos dos anunciantes.

Este magazine apresentava seções fixas, tais como "Chronicas", "Contos e aventuras", "Para recitar", "Comédias", "Percorrendo o Mundo", "Romances", "Conhecimentos úteis", "Diversos", "Páginas de artes", "Curiosidades", "A sciência ao alcance de todos" e "Nossa terra"; e seções esporádicas, como "Primores do engenho humano", "O mez que passa", "Drama" e "Theatro"4.

Ao comparar as seções da revista brasileira com as seções da francesa existem semelhanças. A Je Sais Tout também veiculava romances, cultura geral (numa perspectiva de difusão do conhecimento científico) e esportes, por exemplo. Algumas de suas seções eram intituladas: "GrandsFaits"; "LettresetArts"; "A traversleGlobe”; "Théâtre et Musique”; "Science et Nature”; “La viesociale”; "Élégances"; "Sports”; “Curiosités”; "Nouvelles”; "Roman e Littérature et Poésie". É possível notar que há várias seções comuns às versões brasileira e francesa, embora com nomes eventualmente diferentes: "Para recitar" e "Littérature et Poésie" ou "Theatro" e "Théâtre et Musique". Pouco se sabe a respeito, mas há indícios de que se tratava de um tipo de franquia vendida pelos franceses, pois além da versão que circulava aqui, havia também a I know everything publicada nos Estados Unidos.

${ }^{4}$ A transcrição dos textos presentes na Eu Sei Tudo foi feita literalmente, sem atualização ortográfica. 
Nas edições da Eu Sei Tudo há retratos de personalidades valorizadas à época (devido ao seu conhecimento e/ou área de atuação), imagens, paisagens e reprodução de obras de artes, bem como páginas que apresentavam textos curtos sobre assuntos diversos, como ocorria na seção "Como é fácil saber tudo - Pequena encyclopedia popular".

As capas traziam ilustrações artísticas que apresentavam o nome da revista em diferentes desenhos a cada edição. No miolo da publicação, as imagens veiculadas, coloridas ou em preto e branco, eram distribuídas juntamente com os textos, eventualmente sem compromisso estético ou articulação orgânica com as matérias escritas publicadas na página. Todas as edições contém uma grande quantidade de ilustrações (relacionadas aos textos expostos ou não), nem sempre obedecendo aos protocolos de leitura, fazendo com que o leitor tivesse que mudar sua posição para olhar a imagem e ler a legenda.

Não se constituindo num periódico educativo stricto sensu, a Eu Sei Tudose vinculava a uma perspectiva de difusão de conhecimentos que, via de regra, eram até então construídos em espaços mais escolares ou acadêmicos. Seu caráter universalizante e enciclopedista estão expressos em seu próprio título e em um de seus principais logotipos, um homem com uma cabeça agigantada, em forma de globo terrestre. Sua diagramação era pensada para abranger um público mais amplo e heterogêneo, contendo vários assuntos com o uso de linguagem mais coloquial e inclusão de seções de humor, além de temáticas relativas ao cotidiano do trabalho, do lazer e da vida doméstica. Havia, assim, um convite a diferentes públicos, por meio dos diálogos que as edições procuravam estabelecer com o "leitor".

Grande parte destas revistas de variedades (ou revistas ilustradas) publicadas no Brasil tinha inspiração em publicações análogas, em especial francesas. Paris, ao menos até a década de 1920, aparecia como símbolo do moderno e do civilizado. Desta forma, as ideias que as revistas nacionais veiculavam sobre o atraso tecnológico e cívico do Brasil estiveram muitas vezes enraizadas no modelo francês que desejavam seguir e inserir no país.

Além das revistas ilustradas, um grande número de almanaques começou a aparecer no final do século XIX. Estas publicações também assumiam uma "identidade moderna" pois, eram repletas de ilustrações, textos de rápida leitura e compilavam em um só volume informações pertinentes a todo o ano. Segundo Galzerani (1998), os almanaques faziam parte de um "projeto moderno" e articulavam novidades, hábitos e práticas que sugerissem elegância e bom gosto, além de elementos que apresentassem as cidades brasileiras em progresso.

Ainda de acordo com a autora, os almanaques também buscavam estabelecer um protocolo de leitura fora dos espaços mais institucionais - a escola, por exemplo. Outros meios eram utilizados com finalidades educativas, tais como as fotos e os textos mais curtos, 
com linguagem menos científica, de leitura mais rápida e fácil compreensão. Assim os almanaques podiam chamar a atenção por construírem uma narrativa também através das ilustrações. Estes almanaques eram, portanto, destinados a um leitor moderno,

[...] diga - se leitor culto, apressado, educado, consumidor da mercadoria "almanach", que numa sociedade cada vez mais desencantada e sem mistério busca diversão, prazer, na decifração das charadas. Leitor que no espaço privado de sua casa, junto à esposa e filhos, encontra possibilidade de descontração. (FERREIRA apud GALZERANI, 1998, p. 234).

Seguindo esta tendência, a revista Eu Sei Tudo passou a noticiar, nos exemplares de 1920, a publicação de seu primeiro almanaque, efetivada no ano seguinte:

Indispensavel no lar, no estabelecimento comercial e na repartição publica, contendo a maior somma imaginável de informações uteis, o Almanach de EU SEI TUDO responde a todas as necessidades da família e do negociante, abrangendo em suas páginas, a par de um texto variadíssimo e atttrahente, profusamente ilustrado, a maior somma de informações necessárias á vida quotidiana. (EU SEI TUDO, jul. 1920, p. 10).

O Almanach Eu Sei Tudo foi publicado entre 1921 e 1958, com cerca de 300 páginas por exemplar, grande quantidade de propagandas e imagens organizadas no sentido da leitura de modo que o leitor não precisasse virar a revista para vê-las como, vez por outra, acontecia na revista.

Estes almanaques não tinham seções fixas mas, com frequência, aparecem "Informações sobre o ano"; "Artigos especiais"; "Cousas práticas" e "A mulher em todas as latitudes", seção que será analisada mais detalhadamente no próximo capítulo. Além destas, outras mais constantes foram: "Informações diversas, curiosidades e litteratura" (organizadas em uma mesma seção); "Chronicas"; "Contos"; "Informações úteis em qualquer tempo"; "Informações sobre nossa terra"; "Páginas de arte"; "Quadros e estátuas"; "Informações de calendário"; "Sports"; "Episódios, novelas e aventuras"; "Distrações em casa" e "Diversos".

Seja pela propagação das chamadas belas artes, pelas imagens, pela preocupação com a adoção de hábitos urbanos, dentre outras estratégias, a revista e o almanaque Eu Sei Tudo carregavam, sobretudo, uma função educativa, explicitada através da difusão de conhecimentos múltiplos e na ênfase sobre os modos de vida urbanos "aceitos" em uma sociedade moderna. Assim sendo, por meio da grande quantidade de ilustrações e dos vários assuntos tratados, estas publicações buscavam representar uma concepção de modernidade e criar em seus leitores sensibilidades que caminhassem ao encontro de costumes modernos e urbanos. 
Desta forma, a ideia de moderno estava atrelada a fatores como as reformas urbanas, expressa pelas construções de edifícios e avenidas apresentadas nas figuras, em imagens que deixassem evidente a crescente circulação de automóveis ou, ainda, por meio da difusão de hábitos e costumes entre a população brasileira que seguissem o "modelo francês de cultura e civilização", o qual se disseminava com a veiculação das ilustrações de mulheres europeias, principalmente francesas, tomadas como arquétipos da beleza e classe.

A seguir, veremos como a Revista e o Almanaque Eu Sei Tudo trataram da diversidade étnica e cultural analisando para isso o modo como a África e os africanos, principalmente as mulheres africanas, aparecem em fotos, suas legendas e em textos. Como se pode antever, outras culturas foram secundarizadas e, por repetidas vezes, estampadas ora como sinais de exotismo, ora como indícios de atraso.

\section{O cabelo das mulheres africanas representados nas páginas da revista e do almanaque}

\section{Eu Sei Tudo}

Nesta parte do artigo são analisadas algumas ilustrações e textos veiculados na revista e almanaque Eu Sei Tudo centrados no feminino. Partindo dos vários temas abordados nessas publicações, os quais procuravam distanciar mulheres africanas e europeias fazendo comparações entre as mesmas e sobrepondo estas sobre aquelas, procura-se dar ênfase a um dos elementos que a Eu Sei Tudo evidenciava em suas páginas: os cabelos e penteados das mulheres africanas.

A tentativa de construir uma representação das mulheres africanas, ainda que de maneira sútil, passa pela observação minuciosa de roupas, acessórios e marcas corporais presentes nas diversas culturas africanas. Aliás, estes fatores eram alvos de grande interesse da Eu Sei Tudo, abordados pela revista para demonstrar as "discrepâncias" entre africanos e europeus. Particularmente, abordar-se-á a questão dos cabelos.

"Quanto aos penteados e adornos da cabeça, nota-se copiosa variedade entre os povos da raça negra." (EU SEI TUDO, fev. de 1925, p. 46). 


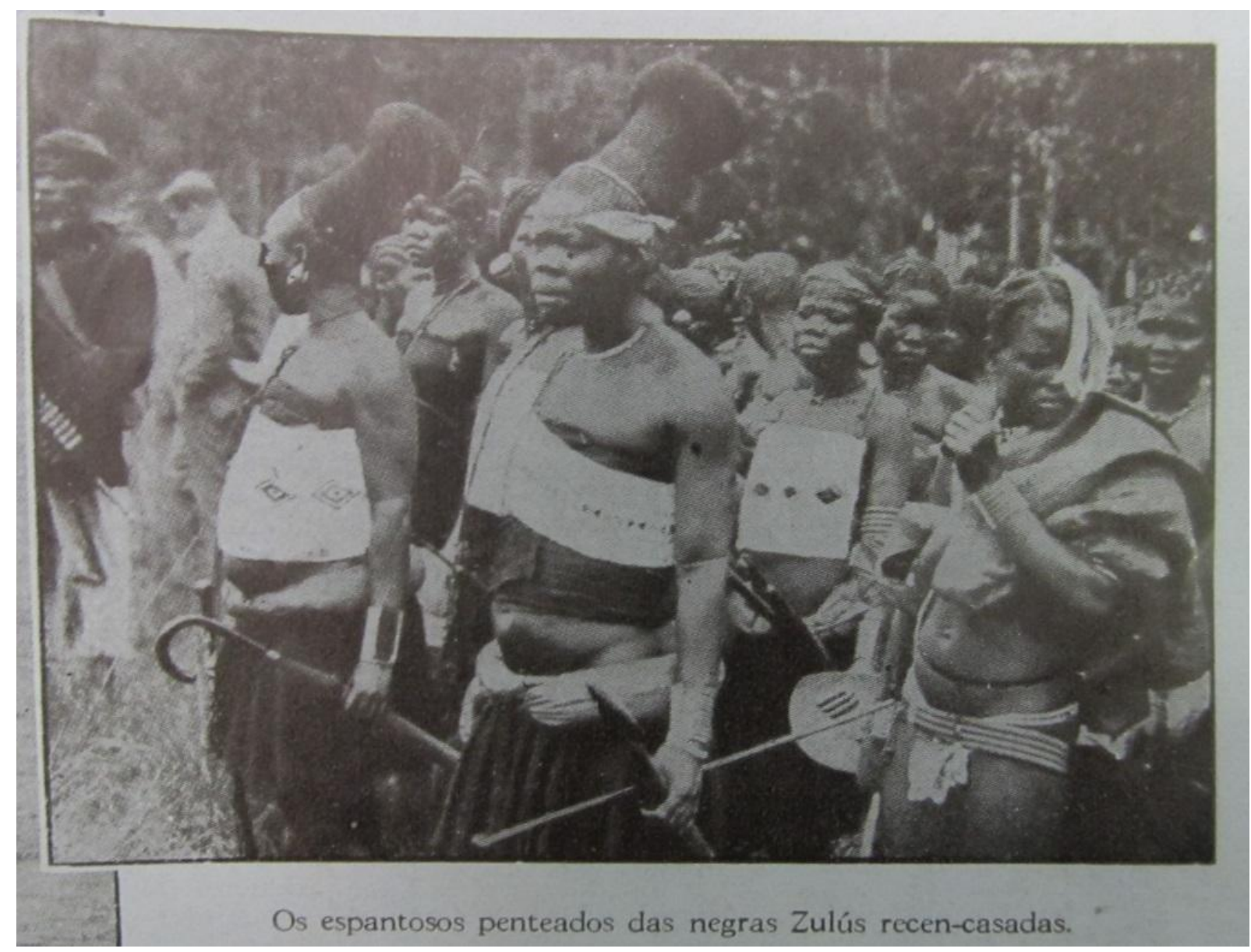

Figura 2 -"Os espantosos penteados das negras Zulús recen-casadas."

Fonte: Revista Eu Sei Tudo, jun. 1928, p. 77.

Quase sempre as legendas que acompanham as imagens demonstram a forma como a revista $E u$ Sei Tudo se dirigia à cultura e mulheres da África, isso porque estão impregnadas da visão eurocêntrica que estabelecia as mulheres europeiascomo padrão de beleza. As adjetivaçõesutilizadas pela revista no trato dos cabelos das mulheres africanas sinalizam para a visão veiculada em suas páginas, geralmentevinculada à ideia do "pitoresco". 


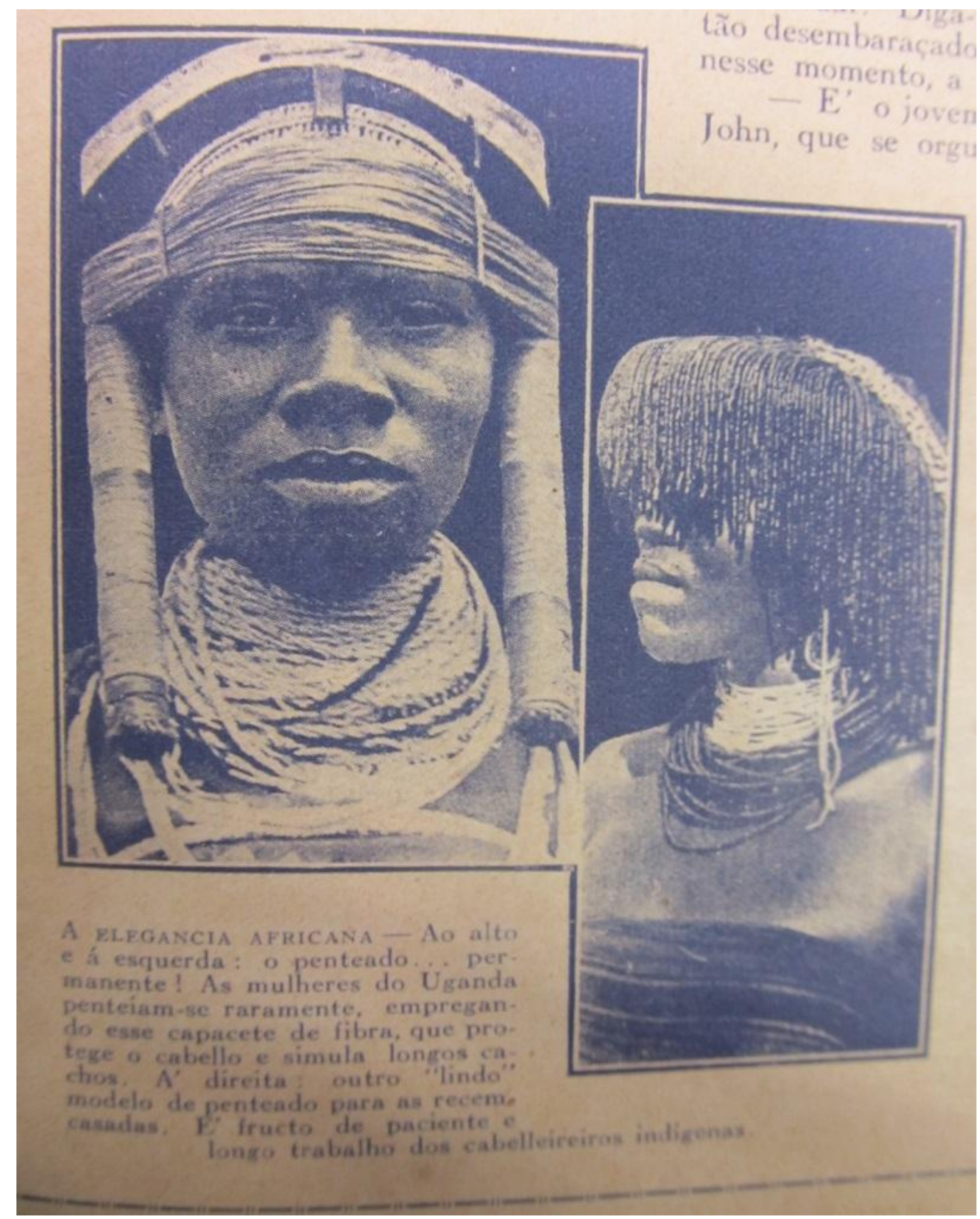

Figura 3 -"A elegância Africana - Ao alto e à esquerda: o penteado... permanente! As mulheres do Uganda penteiam-se raramente, empregando esse capacete de fibra, que protege o cabelo e simula longos cachos. Á direita: outro 'lindo' modelo de penteado para as recém-casadas. É fructo de paciente e longo trabalho dos cabeleireiros indígenas". Fonte: Revista Eu Sei Tudo, nov. 1929, p. 95.

$\mathrm{Na}$ legenda da figura acima, a palavra "lindos", entre aspas, corrobora um olhar de estranhamento sobre os cabelos e penteados das mulheres africanas, o que exemplifica a visão estereotipada e preconceituosa dos europeus sobre outras culturas. Deste modo, é possível verificar uma certa ironia por parte da revista Eu Sei Tudo ao usar este adjetivo entre aspas conferindo uma conotação negativa à beleza e hábitos das mulheres africanas.

Há ainda uma ambiguidade na expressão "elegâncias africanas” pois ora a revista utiliza termos que deixam claro sua estranheza frente aos costumes deste grupo étnico, como

Oficina do Historiador, Porto Alegre, EDIPUCRS, v. 10, n. 1, jan./jun. 2017, 
"selvagens" ou "exóticos", ora faz uso de termos que a disfarçam. Nota-se, portanto, que a Eu Sei Tudo emprega uma linguagem jocosa exacerbando as diferenças existentes entre africanos e europeus na tentativa de transmitir ao leitor a ideia de que a população africana é "atrasada", atribuindo-lhe um caráter curioso.

As interpretações que este periódico veiculava acerca dos penteados e cabelos, nas próximas fotografias, confirmam a construção de uma representação e consequente produção de um imaginário acerca das mulheres africanas.

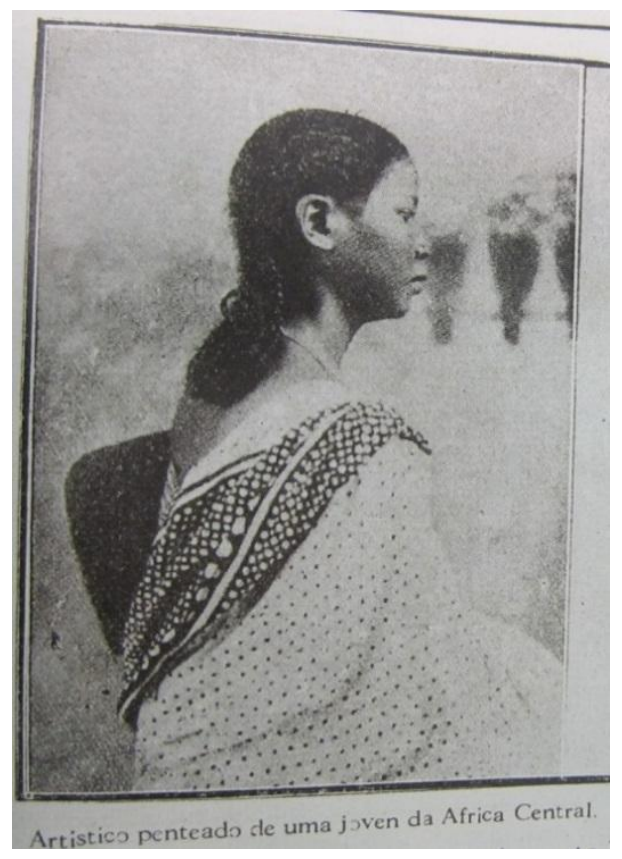

Figura 4 -"Artistico penteado de uma jovem da Africa Central" Fonte: Revista Eu Sei Tudo, fev.de 1925, p. 47.

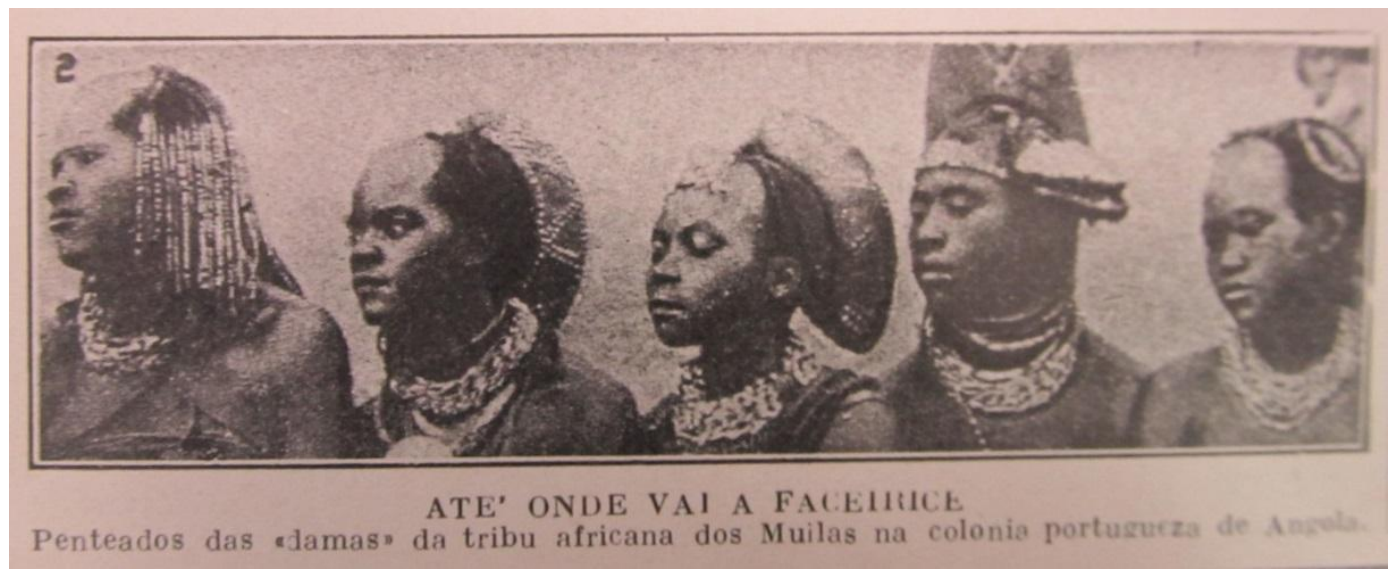

Figura 5-“Até onde vai a faceirice - Penteados das damas da tribu africana dos Muilas na colônias portuguesa de Angola".Fonte: Almanach Eu Sei Tudo, 1921, p. 152.

As imagens e suas legendas reforçam supostas dicotomias entre a cultura africana e o padrão moderno, urbano e europeu de cuidado de si. Quando postas em comparação com 
imagens e legendas sobre as francesas, por exemplo, sinalizam para a construção negativa da alteridade. O texto abaixo, publicado em fevereiro de 1925, mostra como a Eu Sei Tudo se referia ao cabelo das mulheres africanas:

\begin{abstract}
Os adultos usam uma espécie de cabeleira postiça eriçada cobrindo seu lanudo e encrespado cabelo natural e põem especial diligencia em mantê-los sempre na mesma posição de sorte que, á primeira vista parecem que têm cabelos longos e espigados. As mulheres dos litorais seguiam os impulsos naturaes da faceirice, imitando em quanto podem os penteados europeus, pois muitas há que sabem repartir o cabelo com a mesma habilidade com que uma mulher europeia se penteia, formando ondulações e alisando-os numa artística alternativa que lhes dá um aspecto curiosíssimo, um termo médio entre a estupidez da selvagem e a refinada elegância da mulher culta. Com respeito ao penteado masculino não é sua variedade menor do que o feminino, segundo a comarca, tribu, região, etc., se bem que geralmente não vá além do natural modelo da cabeleira encrespada. Alguns acrescem o volume do crânio com uma complicação, que entre nós, teria o aspecto pesado e ridículo mas que entre elles, significa a ultima palavra em distincção e elegância no adorno pessoal. (EU SEI TUDO, fev. 1925, pp. 47).
\end{abstract}

Nota-se que neste último trecho são retomados argumentos próprios à eugenia para legitimar o estranhamento com relação aos cabelos e penteados africanos; a afirmação de que certos modos de arrumar os cabelos davam ao crânio uma aparência maior e que esta aparência, na perspectiva europeia com que são analisados, "teria um aspecto pesado e ridículo". Além disso, a comparação feita a partir dos termos "estupidez selvagem" e "refinada elegância da mulher culta", para sugerir que as africanas buscavam "imitar" os cabelos e penteados das europeias, e a utilização das palavras "espigados" ou "encrespado" também sugerem essa perspectiva ao enaltecerem o padrão europeu.

As muitas imagens, legendas e textos presentes na Eu Sei Tudo parecem considerar as diferentes vertentes da antropologia tal como praticada no século XIX: de um lado, uma atenção à anatomia dos corpos; de outro, um olhar para as especificidades culturais dos ditos "não civilizados"; nas palavras de José Guilherme da Silva e Sá e Ricardo Ventura Santos (2008), estão contempladas no periódico tanto a "antropologia física" quanto a "antropologia social/cultural", ambas apontando, naquele período, para desigualdades raciais e culturais.

A pesquisadora Nilma Lino Gomes, tão reconhecida por sua militância contra a discriminação e o preconceito, e intelectual com ampla produção científica nas áreas de educação e antropologia tratou, especificamente, do cabelo negro, seja como alvo de manifestação do preconceito seja como lugar de prática de afirmação.

“O cabelo do negro, visto como 'ruim', é expressão de racismo e 
desigualdade racial que recai sobre esse sujeito. Ver o cabelo do negro como 'ruim' e do branco como 'bom' expressa um conflito." (GOMES, 2006, p. $3)$.

Atrelar os cabelos femininos africanos a adjetivos depreciativos expressa as tensões que envolviam a busca pela determinação de um padrão estético. As maneiras como a Eu Sei Tudo tratava a questão eram também um "critério de classificação racial para apontar quem é negro e quem é branco em nossa sociedade" (GOMES, 2006, p. 3). Em contrapartida, a representação das mulheres brancas sempre esteve vinculada a adjetivações mais positivas: "beleza ímpar", "graciosidade" e "elegância" e "sofisticação", entre outros exemplos.

Deste modo, a questão que se põe aqui está ligada aos mecanismos discriminatórios que foram criados e, também, relacionada às significações e aos sentidos dados à cultura africana de uma forma geral. Abordar o cabelo é um fator importante, mas compreender como foi produzida uma imagem acerca dos cabelos de homens e mulheres africanos é ainda mais essencial posto ter sido determinante para sua representação estereotipada.

\section{Considerações finais}

Em suma, este artigo buscou discutir a maneira como a revista Eu Sei Tudo corroborou com a construção de representações estereotipadas acerca dos cabelos das mulheres africanas, a partir da análise de imagens e legendas veiculadas por esta revista de variedade no século XX.

A Eu Sei Tudo, ainda pouco estudada entre nós, se revela fonte profícua para a pesquisa histórica em geral e para a pesquisa em história da educação em particular. Este magazine pode ser usado para tratar da educação feminina, para o estudo de práticas de leitura, para a análise das relações culturais entre Brasil e França, enfim, para uma enorme variedade de temas.

As ilustrações propagadas pela revista $E u$ Sei Tudo são carregadas de significados que foram, em parte, responsáveis por construir estereótipos acerca das mulheres africanas. Ao representar estas mulheres, a revista enalteceu um tipo de beleza, o da mulher branca, por meio da articulação de imagens que construíam um discurso visual que fortalecia padrões eurocêntricos.

A partir dessas representações veiculadas nas páginas da $E u$ Sei Tudo, uma identidade sobre africanos e afrodescendentes foi sendo (de)formada; preconceitos de gênero e raciais foram propagados e grupos sociais hierarquizados. 
Em que pesem os avanços, ainda é por vezes folclórico o tratamento conferido à África e aos africanos, especialmente quando temas como "alimentação", "vocabulário", “personalidades negras", "influências na música” são os únicos abordados. Quer dizer, o que se toma como cultura africana e afro-brasileira ainda precisa ser expandido e ressignificado. Conhecemos muito pouco a história da África, o que é resultado inclusive dessa visão linear e positivista da história, do eurocentrismo e da propagação (e manutenção) da perspectiva dos países dominantes durante o período imperialista. Mesmo com esforços, continuamos estudando a cultura africana e afro-brasileira do ponto de vista do colonizador, eventualmente reiterando representações orientadas pelos modelos e padrões do conquistador.

A difusão da ideia de uma suposta "democracia racial" agrava este quadro, mascarando uma realidade marcada pela exclusão de enormes parcelas da população, reinventando e reconfigurando certos estereótipos. Mesmo com a aprovação da Lei $\mathrm{N}^{\circ}$ $10.639 / 2003$, muito ainda precisa ser feito para que este decreto se torne uma prática escolar cotidiana, inclusive capaz de se contrapor ao preconceito que tem na escola um de seus lugares de mais amplo exercício, seja através da evidência de alguns aspectos culturais daquele vasto continente, seja no silenciamento de outros.

\section{Referências Bibliográficas}

BACZKO, Bronislaw. Imaginação social. In: Enciclopédia Einaudi. Antropos-Homem. Lisboa: Imprensa Nacional-Casa da Moeda, 1985, vol. 5, p. 296-332.

BERMANN, Marshall. Tudo que é sólido desmancha no ar. São Paulo: Companhia das Letras, 1987.

BRASIL. Lei $\mathbf{N}^{\mathbf{0}} \mathbf{1 0 . 6 3 9}$, de 9 de Janeiro de 2003.

CHARTIER, Roger. O mundo como Representação. Estudos avançados. [online]. São Paulo, v. 5, n. 11, 1991, p. 173-191.

D’AVILA, Jerry. Diploma de brancura. Política social e racial no Brasil, 1917-1945.

São Paulo, Editora da UNESP, 2006, p. 17-47.

DOURADO, Rosiane de Jesus. As formas modernas da mulher brasileira (1920 -1939). Rio de Janeiro, 2005, p. 61-97.

FERNANDES, Arminda. Nela Martins Lopes. A imagem da mulher na revista Eu Sei Tudo na primeira metade do século XX. Faculdade de Educação de Minas Gerais, 2009, p. $1-11$. 
. Ser mulher mãe:a educação da saúde nas páginas da Eu Sei Tudo nas primeiras décadas do século XX (1918 - 1932). 2009.Dissertação (Pós Graduação em Educação)Faculdade de Educação de Minas Gerais, Belo Horizonte, 2009.

GALZERANI, Maria Carolina Bovério. O Almanaque, a locomotiva da cidade moderna: Campinas décadas de 18870 e 1880. 1998. Tese (Doutorado em História)- Faculdade Estadual de Campinas. Campinas-SP: [s.n.]. 1998.

GOMES, Nilma Lino. Trajetórias escolares, corpo negro e cabelo crespo: reprodução de estereótipos ou ressignificação cultural? Revista Brasileira de Educação, n. 21, set./out./nov./dez. 2002, p. 40-51.

Sem perder a raiz:Corpo e cabelo como símbolos da identidade negra. $1^{\mathrm{a}}$ edição. Minas Gerais: Autêntica, 2006.

MAUAD, Ana Maria Mauad. Sob o signo da imagem. A Produção da Fotografia e o Controle dos Códigos de representação Social da Classe Dominante, no Rio de Janeiro, na Primeira Metade do Século XX. 1990. Dissertação (Mestrado em História)- Universidade Federal Fluminense. Niterói - RJ. 1990.

MUDIMBE, Valentin Yves. Ainvenção da África: Gnoses, filosofia e a ordem do conhecimento. Mangualde, Luanda: Edições Pedago; Edições Mulemba, 2013.

SA, Guilherme José da Silva e; SANTOS, Ricardo Ventura; RODRIGUES-CARVALHO, Claudia and SILVA, Elizabeth Christina da. Crânios, corpos e medidas: a constituição do acervo de instrumentos antropométricos do Museu Nacional na passagem do século XIX para o XX.Hist. cienc. Saúde-Manguinhos [online]. 2008, vol.15, n.1 [cited 2014-06-20], p. 197 208 .

SAID, Edward W. Cultura e Imperialismo. São Paulo: Companhia das Letras. 2011.

SANTOS, Dominique Vieira Coelho dos. Acerca do conceito de representação.Revista de Teoria da História. Ano 3, n. 6, Goiás, p. 27-53, dez. 2011.

SANTOS, Rogério Fernandes. A influência dos estereótipos no julgamento da veracidade de enunciados. 2008Dissertação (Pós Graduação em Psicologia)- Universidade Federal da Bahia. Salvador, 2008.

\section{Fontes Primárias}

Almanach Eu Sei Tudo, Rio de Janeiro: Companhia Editora Americana, 1921 a 1929. Revista Eu Sei Tudo, Rio de Janeiro: Companhia Editora Americana, junho de 1917 a dezembro de 1929. 